\title{
Health spending still increasing but space science stalled
}

What the US government does for (and to) science in 1987 is bound to be influenced by the imbroglio of the Iranian arms affair - the most serious political scandal for a decade, variously known as "Irangate", "contragate" and "Iranamok".

At the very least, the long process of inquiry will significantly affect the capacity of the President to govern. But as the fiasco has acquired its present importance because the administration chose not to tell the Congress what was going on, distrust between the two parts of government has been magnified. With both houses of Congress now controlled by Democrats, a Republican president with two years left in office will find it harder than ever to persuade congressmen to his way of thinking.

Arms control will be an early issue between these two parts of the government. More than half of the Senate's $100 \mathrm{mem}$ bers have already signed a letter urging the President to bring back the United States within the limits of the SALT II treaty; they have in mind the deployment in November of a B52 bomber equipped with nuclear-armed cruise missiles which put the United States beyond bounds. But there will be more general dissent from the administration's policies on arms control. Enthusiasm for military research and particularly for the Strategic Defense Initiative (SDI), will further decline.

By contrast with SDI, the National Institutes of Health (NIH) seem destined to flourish yet again. Last year, NIH's budget of $\$ 6,100$ million was considerably more than the administration's request. Growing concern about AIDS (acquired immune deficiency syndrome) can only loosen spending. If there is a cloud on NIH's horizon, it is the growing strength of the animal rights movement. The legislation that Congress must now take up could have a dramatic effect on the use of animals in research.

The future pattern of the US space programme should soon become a little clearer. The Challenger disaster and the two succeeding unmanned launch failures virtually crippled the programme for a time. Although launches by the National Aeronautics and Space Administration (NASA) have now resumed, many scientific payloads have been badly delayed. Space scientists will ask that NASA should augment its fleet ' of expendable launch vehicles, but, with an appropriation of $\$ 2,100$ million for a replacement shuttle already agreed, NASA is likely to keep most of its eggs in the shuttle basket.

Early this year, the space science board of the National Academy of Sciences will issue an important prospectus for the US civilian space programme in the next century. The board will argue for a programme of applications contributing to human welfare. But until the shuttle flights are resumed, the present crisis can only worsen.

Elsewhere, the outlook is not so bleak. Congress has appropriated $\$ 16.2$ million to start construction of the Continuous Electron Beam Accelerator Facility at Newport News, Virginia, a welcome shot in the arm for nuclear physics.

In high-energy physics, the good news is that the Secretary of Energy, John Herrington, has declared himself in favour of seeking funds to begin work on the Superconducting Super Collider; part of the interest in the coming year will be whether he can persuade the White House Office of Management and Budget, and then Congress, to share this view. The Department of Energy will also be pushing for an international effort to build the next generation of fusion reactors, one of the issues agreed at the Reagan-Gorbachev summit at Geneva in 1985 .

In the past year, the Department of

\section{Prospects for 1987 United States \\ Tim Beardsley/Joseph Palca in Washington}

Energy also provided much of the impetus for one of the year's most interesting scientific debates: whether to sequence the entire human genome and, if so, when and how. Opinion seems to have hardened in favour of first making a physical and genetic map of the genome, using the interval to improve sequencing technology and the handling of the data that will emerge. The Energy Department, through its national laboratories, has already started on the mapping project,' while the Howard Hughes Medical Institute is providing funds for university efforts. Serious discussions of an international effort are now under way, especially with Japan.

The Environmental Protection Agency. (EPA), which has taken a strong position on the protection of the stratospheric ozone layer, will be shaping the US negotiating position at international negotiations at Geneva. Some believe that a protocol to limit emissions of chlorofluorocarbons can soon be achieved. EPA will also be concentrating on research on the greenhouse effect and development of mitigation strategies for indoor radon pollution.

One issue certain not to be resolved in 1987 is the regulation of biotechnology. The release of genetically altered organisms was a political hot potato last year, while the administration's attempts to de-

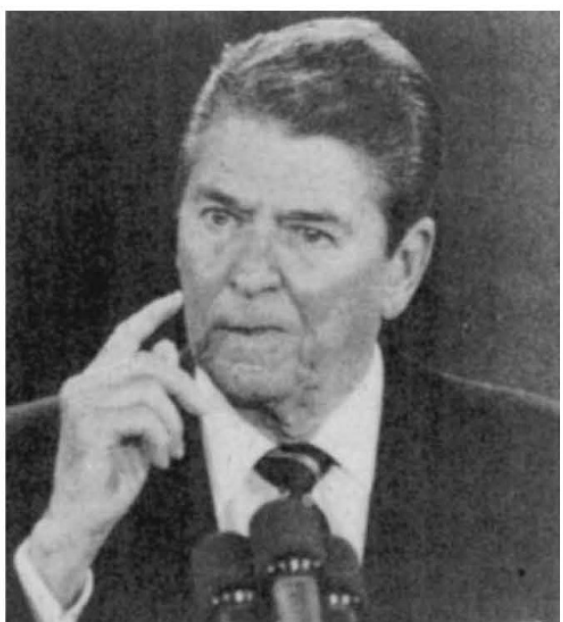

Reagan's embarrassment: admitting his decision to sell armis to Iran in his 19 . November press conference.

velop a coordinated framework for regulation failed to still the many criticisms of its proposals. It will be interesting to see how many more industries and institutions choose to conduct field trials overseas.

Congress and the administration will also be paying more attention to the health of US industry, under the rubric of international competitiveness. The United States is worried that its trade deficit continues to grow, and that even its preeminence in high-technology products is being eroded. On the grounds of national security as well as the well-being of the economy, the government seems ready to help the semiconductor industry, which hopes to mount a collaborative manufacturing effort so as to compete more effectively with the Pacific Rim nations.

The impact on science and research of last year's Tax Reform Act remains to be assessed. Universities and charitable foundations cried foul as the new laws removed many of the incentives for charitable giving. Universities are generally concerned about the deterioration of their physical plant, while the change in federal regulations governing reimbursement for the indirect costs of research grants will force research universities to work even harder to make ends meet.

With the change of the political flavour of the Congress and the political furore at the White House, it will be some time before federal science policy is set on track. The Office of Science and Technology Policy finally has a new director, but his voice has yet to be heard in a forceful way. Erich Bloch, director of the National Science Foundation (NSF), has high goals for his agency, while it is rumoured that there is a one-third increase of funds in the federal budget for 1988 , due to be released next week. If true, that could further add to NSF's importance in federally supported research. But choosing where to place research dollars will become even harder as growing demand continues to outstrip the growth of supply. 